\title{
Studies on Creativity Enhancement of Contemporary College Students
}

\author{
1 Xiaohuan Zhong, ${ }^{2, a, b}$ Zhongliang Liu \\ ${ }^{1,2}$ Institute of Ideological and Political Education, Nanjing Forestry University,Nanjing, China, 210037

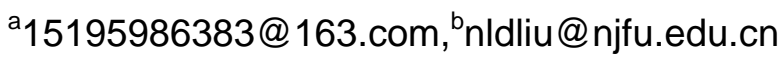

Keywords: Creativity, Innovation,College Students,College Education.

\begin{abstract}
Contemporary college students are not only important national talents that are cultivated, but also senior personnel, builders and successors of the country's future. To improve the level of college students' innovative ability would play a huge role in our country's nation-building. Still, viewing from the current China' s university innovation level, the status can not be satisfied. The level of students' creativity is generally low. As future builders and successors, we should have the urgency and forward-looking enough to improve our students' awareness of innovation. This is an era of rapid development when a higher requirement for college students' innovative ability has been proposed. To college students, we are on the one hand facing this great challenge and on the other confronting great opportunities.
\end{abstract}

\section{Introduction}

Innovation is a word we often mention, especially in the twenty-first century, when the country's development is inseparable from science and technology. The development of science and technology, on the other hand, can not be separated from innovation[1-5]. Innovation performs as the network of interaction between different actors and institutions. In this network, any node may become innovative and to achieve specific space. Thus, innovative behavior can be spot in different technical, institutional, or knowledge aspects. Many achievements of modern economic and technological development are fostered in universities and can be seen in the practical application of the university. We can see that the university has a good atmosphere for innovation, and as part of a university, college students has a good condition and advantage of engaging in innovative activities. Thus, keen to cultivate college students' innovative ability has its own possibility.

Improve students' innovative ability is of great significance. To enhance the awareness of innovation among college students is an important topic. Currently, the transformation of our knowledge into the results still needs university students to do a lot of work. Moreover, college students are the indispensable strength of science and technology and economic construction, which is the initial purpose of developing the country through science and education. It is a glorious mission that our country gives this generation. Only by continuously improve innovation capability of contemporary college students ,can we inherit and carry forward the achievements of China's advanced culture and history in order to make a great task of Chinese revival. Only by making continuous efforts can we having new discoveries and exceeding other countries in the world. Therefore, to encourage college students to actively participate in innovation activities poses great significance on the national and the world.

\section{Students' lack of innovation awareness and main performance of innovation}

Innovative concepts and creative desires are missing:Development of innovation capacity and innovative behavior are based on innovative ideas and creative desires. If a person does not have innovative ideas and innovation desire, than he will not find his new potential, don' $t$ even mention to carry out new exploration. Although the survey showed that most students are not satisfied with their status, but they are most often just grumble, moan and groan, lacking confidence in their own actions and a strong spirit of innovation. 
Innovative thinking capability is missing:In modern society, the overall level of college students' creative thinking ability can not be viewed optimistically, and can be mainly seen in several ways: the lack of in-depth thinking, courage to seek another way and independence self-learning ability. During study, consider of the issue and deal with the problem is stereotyped, and there are no innovation and breakthroughs. Thus, we must encourage college students to broaden their horizons, read more books, observe more, think more, and learn to look at the problem innovatively in order to cultivate habits of creativity.

Interest and perseverance in innovation is missing: As the saying goes, interest is the best teacher. With the rapid development of the digital age, contemporary universities' campus life is very rich. Students' interests are very broad. Schools should make full use of school resources to create a good academic atmosphere, in order to stimulate students' potential. Sustained efforts should be paid for interest, rather than giving up halfway. Only by have the droplets wear stone spirit, can we have a qualitative leap.

Necessary innovation perseverance is missing:Perseverance is the concentrated expression of initiative and self-motivation, which is consciously targeted by human. Their own actions are regulated and governed by objectives in order to overcome all difficulties and mental processes and adhere to realize their goals. From the survey we can see that most of the students have been aware of the important role of a person's perseverance in innovation activities, but in actual work they are often inconstant and give up what they pursuit.

With the prevalence of the internet, incoming of Western thought and other Chinese social pressures are now presenting growing problems. Thinking and behavior activities of contemporary college students also appeared to have a lot of separation. Innovation among college students is also facing enormous challenges. The internet is a double edged sword, giving our graduates infinite knowledge, but the openness of the internet makes a lot of college students addicted to the unreal world games, and can not face up to their responsibilities. There are a variety of psychological problems among a lot of students, such as a variety of psychological problems and moral defects, which no doubt set up obstacles for the improvement of students' creative ability.

\section{Specific ways to improve the awareness of innovation and creativity among college students}

Take the initiative to create a dynamic and innovative atmosphere on campus:Create innovative atmosphere can provide a good environment atmosphere for innovation behavior, positive innovation scene allows college students to produce their own innovative ideas and inspiration. First, the university now has a teacher to lead students to develop a wide variety of student groups, various student organizations should play a leading role, to hold more positive and useful student activities, improve their ability to innovate, in addition, college students should take full use of resources such as libraries, student activity center that are provided by colleges and universities. In addition, college students' horizon should not just limit to college campuses. They can use their spare time to participate in extracurricular activities or take hold of internship opportunities and so on. Only by constant practice can we make something on the books be transformed into real life, and found the problem and then solve the problem. This will be an innovative process.

Cultivate the habit of college students studying science and thinking habits:Zhu Qinshi academician expressed in his speaking that when it comes to innovation ability, the ability of outstanding scientists being able to keeping new achievements in various fields, is that they have a love of science, and constantly develop their own academic accomplishment, constantly study new things. The quality of perseverance is important to their success, which requires us to abandon society unhealthy tendency that confuse us and to find their own interests and by extension, apply them on the academia area. Stick tirelessly in the discovery and solve problems; secondly, we must start our thinking ability, and can not use a single look at the problem, instead, persisting multi-angle multi-level problem solving. We also need to have a scientific attitude towards learning, which tells us that at any time to do anything, we should be single-minded, not in fits and starts, and have the perseverance to solve the problem. 
Seriously study and accumulate basic knowledge is fundamental to the culture of innovation:Good foundation of cultural knowledge is precondition of making innovations generated. Basics no entrenched as a prerequisite, there will not be a good outcome of innovation, quality and innovative result will be after a long period of study and exploration. Kai-fu Lee believe that during university study, college students must learn to grasp good opportunity, lay the solid basis of professional courses and to learn professional knowledge. In addition, if there is no good foundation, college students would be difficult to really understand the application of advanced technology. Therefore, to lay the foundation of knowledge has a crucial role to the propose of new discoveries. However, we must not give up the extension of the basic knowledge and discovery of new knowledge and problem as one learns the basics knowledge, otherwise there would be more harm than good.

Create a better campus cultural environment for the growth of innovative talents:Create innovative education and requirements of the new campus cultural environment is an important part to improve the innovative capability of college students. The life of people is inseparable from the environment, and the influence of a good campus environment can also make us more willing to participate in the activities organized by the school, such as school community activities.

From the teachers' point of view, they should play a leading role in academic.Excellent atmosphere can give students a good effect.Furthermore, harmonious campus culture between teachers and students can improve the level of university innovation strength,which will promote students' learning interest and innovation enthusiasm.In school, the teacher is students' guidance so that the teacher should set themselves an example to others. Thus, their new discovery and experiences can be inherited by students enventually.and then it will improve the innovative ability of college students eventually. Some innovation exhibition can be put in teaching building of school dormitory, to achieve the effect of propaganda.

Develop a scientific study habits and thinking habits:Another important way to improve college students' innovation ability is to cultivate correct scientific learning and thinking habits. A good study habits help to improve the learning efficiency and develop thinking space.The Specific measures are as follows.

Improve the sensitivity of things.

found one' s own points of interest.

Survey the world with the scientific view.

Improve their ability of thinking constantly.

Good at communication with classmates and the professor.

Learn to use a variety of ways of thinking to solve the problem.

\section{Conclusion}

The improvement of the college students' innovative ability is an arduous task, which is impossible to be solved in a short period of time.Moreover, The historical task is endowed with many difficulties and obstacles.Thus, the government should give colleges more policy encouragement and material investment to make college students have a good learning environment.While, the college students should cherish the chance at school,make full use of school resources to bring forth new ideas in scientific research and strive to become the pillars of the society.Furhermore,it is the urgent problems that we need improve the innovative ability of contemporary college students.The ability makes for educational enterprise,comprehensive national power,even the key to improving the quality of human resources and to the realization of the rise of the chinese nation.Besides, From the current situation of college students' innovation, it is imperative to cultivate students' innovation consciousness and improve their innovative ability.

\section{References}

[1]Nikki Tocco, The American Journal of Surgery(2013) 206:269-279 
[2]Ailing Chena, Liping Lib, Xingsen Lic, Jun Zhanga, Lei Donga(2013) Procedia Computer Science 17:1194-1201

[3]Marcelo Seido Nagano, Juliano Pavanelli Stefanovitz, Thais Elaine Vick(2014) Journal of Engineering and Technology Managemen 33:63-92

[4]B.A. Sabel(2013) Open Innovation in the Food and Beverage Industry 369-387

[5]Carla Haelermans, Kristof De Witte(2012) European Journal of Operational Research 223:541-549 